Original Article

\title{
IN SILICO STUDY OF MONOSACCHARIDE COMPOUNDS EFFECT ON B CELL RECEPTORS (BCR) FROM NONI FRUIT (MORINDA CITRIFOLIA)
}

\section{LA ODE MUHAMMAD ANWAR ${ }^{1,2}$, RUMIYATI², EDIATI SASMITO²}

${ }^{1}$ Faculty of Pharmacy, Muslim University of Indonesia, Makassar, Indonesia, ${ }^{2}$ Faculty of Pharmacy, Gadjah Mada University, Jogyakarta, Indonesia

Email: la.ode.muhammad.anwar@mail.ugm.ac.id

Received: 09 Aug 2019, Revised and Accepted: 11 Oct 2019

\section{ABSTRACT}

Objective: Noni fruit has been widely used as a treatment. The content of saccharides in noni can affect the immune system, especially as independent antigens (TI) against B cell receptors (BCR). TI can produce antibodies without being influenced by T cells. Therefore, this study aims to look at the effect of IT on BCR with the in silico method approach.

Methods: Ligands were obtained from Zink Web and macromolecules were obtained from Protein Data Bank with code 2H32. Ligand optimization using VegaZZ software and macromolecules is optimized using UCSF Chimera software. Ligands and macromolecules are docking using MOE software.

Result: The results showed that monosaccharide compounds have an interaction with BCR, which is characterized by a decrease in free energy. The D-Galactose compound has the largest binding affinity of- $4.80 \mathrm{kcal} / \mathrm{mol}$.

Conclusion: Monosaccharide compounds are independent antigens (TI) of noni (Morinda citrifolia) that can affect on B cell receptors (BCR), which have identical epitopes.

Keywords: Monosaccharide, In silico, Morinda citrifolia, Independent antigen (TI), B cell receptors (BCR)

(c) 2019 The Authors. Published by Innovare Academic Sciences Pvt Ltd. This is an open access article under the CC BY license (http://creativecommons.org/licenses/by/4.0/) DOI: http://dx.doi.org/10.22159/ijcpr.2019v11i6.36350

\section{INTRODUCTION}

Noni is a plant that has been widely used by residents of Polynesia as a treatment [1]. Noni fruits contain saccharide compounds that affect the immune system [2]. According to the research, the total saccharides which are mainly contained in noni fruit are GalAp (53.6 mol\%), Araf (13.6 mol\%), Galp (17.9 mol\%) and Rhap (9.5 mol\%) [3]. Many nonprotein antigens, such as saccharides, lipids, and nucleic acids, stimulate antibody production in the absence of $\mathrm{T}$ helper cells, and the response is called an independent thymus or TI [4]. T-independent antigens can stimulate the proliferation and differentiation of $\mathrm{B}$ cells without the aid of $\mathrm{T}$ cells. The most important TI antigens are saccharides, glycolipids, and nucleic acids. All of these antigens can induce the production of specific antibodies in animals that lack T cells. These antigens cannot be processed and presented in association with MHC molecules, and therefore they cannot be recognized by CD4+T helper T cells. Most TI antigens are multivalent, consisting of repetitive identical antigenic epitopes. Such multivalent antigens can induce maximal crosslinking of the BCR (B cell receptor) complex to certain B cells, which leads to activation without the help of $\mathrm{T}$ cells [5]. Therefore this research is to see the effect of saccharide compounds, especially monosaccharides on B cell receptors (BCR) as independent antigens with in silico method.

\section{MATERIALS AND METHODS}

Preparation of chemical compound models

The preparation of the chemical compound model was done by downloading the compound ligand model based on the research conducted by Bui [3], then the compound was downloaded on the ZINK Web (https://zinc.docking.org/). Macromolecules are downloaded from the Protein Data Bank (http://www.pdb.org) with code $2 \mathrm{H} 32$.

\section{Optimization of compounds}

Optimization of plant compounds using the VegaZZ program After obtaining the compound. Then the structure is opened using VegaZZ. Added hydrogen molecule. The charge is fixed by adding the gasteiger charges and given the autodock forcefield. Minimization and search for conformations were carried out in 3000 steps. Ligan are stored in. mol2 format.

\section{Preparation of target macromolecules}

Macromolecular preparation using the UCSF Chimera program. Macromolecules are separated ligands and all nonstandard residues. Next is the docking preparation and separation of the $\mathrm{H}$ atom. Macromolecules stored in. pdb format.

Table 1: Results of analysis of several monosaccharide compounds against B cell receptors

\begin{tabular}{lll}
\hline Compounds & Binding affinity (kcal/mol) & RSMD \\
\hline D-(-)-Arabinose & -4.38 & 0.71 \\
Beta-D-Glucose & -4.74 & 0.92 \\
D-Galactose & -4.80 & 1.01 \\
D-Glucuronic acid & -4.64 & 0.71 \\
L-Rhamnose & -4.56 & 1.10 \\
\hline
\end{tabular}




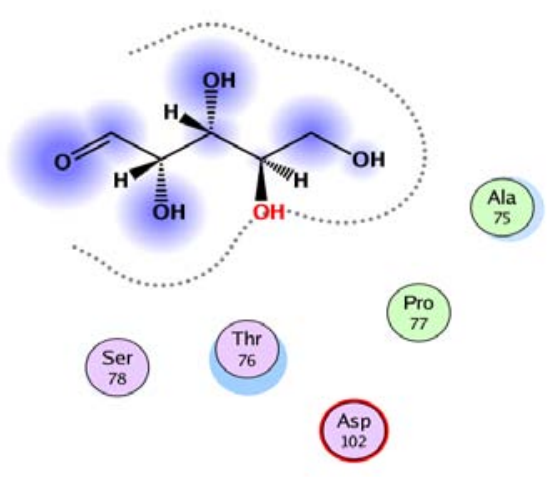

D-(-)-Arabinose

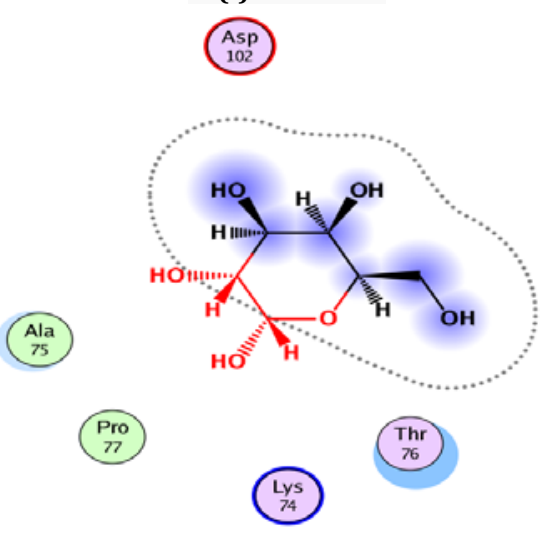

D-Galactose

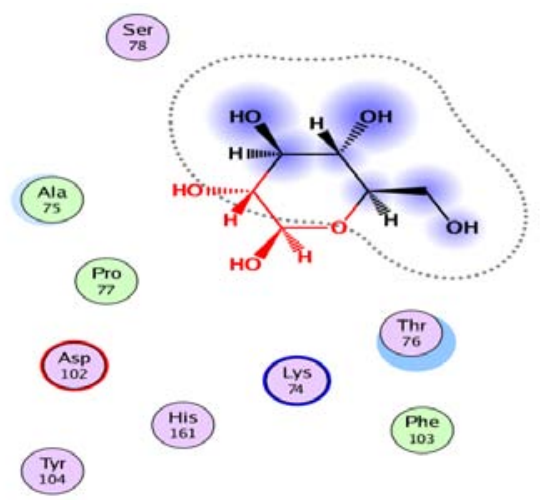

Beta-D-Glucose

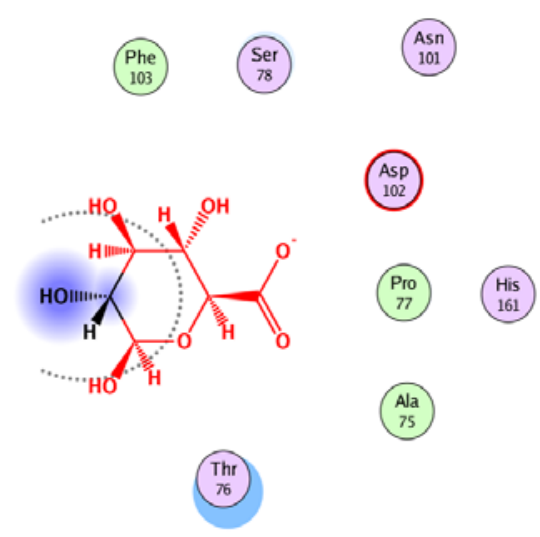

D-Glucuronic acid

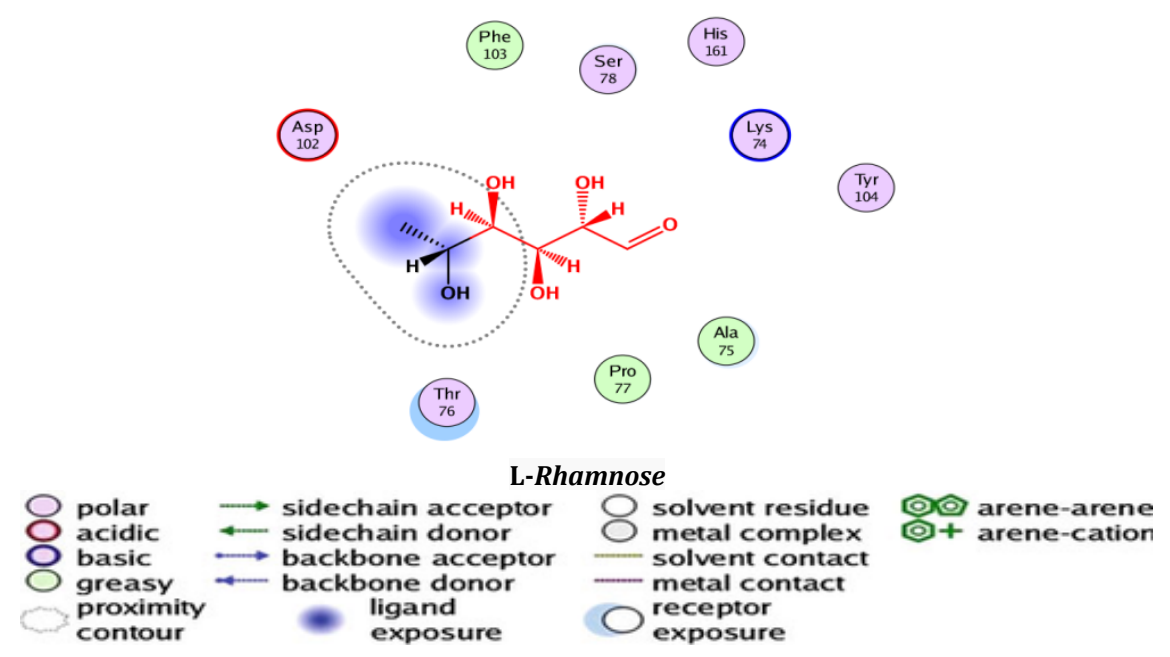

Fig. 1: Interaction of ligands and amino acids

\section{Molecular tethering and visualization}

Molecular tethering is done using the MOE program. The tethered and optimized macromolecule and ligand structures separately are stored in the same folder.

\section{RESULTS AND DISCUSSION}

The results of research that has been done without that monosaccharide compounds affect BCR with a decrease in Gibs energy. The use of the in silico method guarantees to screen of plant compounds more easily and efficiently for trial and error can be overcome easily. The in silico study found that some saccharide compounds can bind to BCR. The decrease in Gibs energy $(\Delta G)$ in compounds D-(-)-Arabinose, Beta-D-Glucose, D-Galactose, DGlucuronic acid, and L-Rhamnose shows that there is an effect of monosaccharides on B cell receptors. The D-Galactose compound has the greatest affinity bond, which is $-4.80 \mathrm{kcal} / \mathrm{mol}$. With interactions on several amino acids such as Ala75, Asp102, and Thr76. This illustrates that the D-Galactose compound can act as an antigen that can bind to cell B receptors. This is because monosaccharides are antigens with identical and recurring epitopes. The introduction of $\mathrm{T}$ cells from glycopeptides depends on the structure of the peptide and glycol antigen sections. Glycopeptides containing mono or oligosaccharides, which are produced by processing natural glycoproteins that have zwitterionic [6]. Zwitterionic in saccharides, which have positive and negative alternating charges in each repeating unit, are then recognized by antigen-presenting cells (APC) and are processed through oxidative reactions by class II histocompatibility pathways (MHCII) to T cells $[7,8]$. Non-zwitterionic compounds, which have only negative or no charge. As a result, it cannot bind to MHCII so that it cannot activate $\mathrm{T}$ cells [9]. Nevertheless, antibodies can still be produced. Most of the antibodies produced from this antigen are IgM 
and several sub-types of IgA and IgG [5]. This research is very useful in the search for new antigens that can be developed. The use of saccharide compounds generally does not have toxic effects and a good level of safety.

\section{CONCLUSIONS}

Monosaccharide compounds are independent antigens (TI) in noni (Morinda citrifolia) that can on BCR which have identical epitopes in influencing the immune system.

\section{AUTHORS CONTRIBUTIONS}

All the author have contributed equally

\section{CONFLICT OF INTERESTS}

Declare none

\section{REFERENCES}

1. B West, CJ Jensen, J Westendorf. A new vegetable oil from non (Morinda citrifolia) seeds. Int J Food Sci Technol 2008;43:1988-92.

2. E Sasmito. Polysaccharide rich fraction of noni fruit (Morinda citrifolia L.) as doxorubicin co-chemotherapy: evaluation of catalase, macrophages, and TCD8+lymphocytes. Sci Pharm 2015;83:479-88.

3. AKT Bui, A Bacic, F Pettolino. Polysaccharide composition of the fruit juice of morinda citrifolia (Noni). Phytochemistry 2006;67:1271-5

4. TV Obukhanych, MC Nussenzweig. T-independent type II immune responses generate memory B cells. J Exp Med 2006;203:305-10.

5. AK Abbas, AHH Lichtman, S Pillai. Cellular and Molecular Immunology E-Book. Elsevier Health Sciences; 2017.

6. B Dzhambazov. The major T cell epitope on type II collagen is glycosylated in normal cartilage but modified by arthritis in both rats and humans. Eur J Immunol 2005;35:357-66.

7. BA Cobb, Q Wang, AO Tzianabos, DL Kasper. Polysaccharide processing and presentation by the MHCII pathway. Cell 2004;117:677-87.

8. J Duan, FY Avci, DL Kasper. Microbial carbohydrate depolymerization by antigen-presenting cells: deamination prior to presentation by the MHCII pathway. Proc Natl Acad Sci USA 2008;105:5183-8.

9. FY Avci, X Li, M Tsuji, DL Kasper. Carbohydrates and T cells: a sweet twosome. Semin Immunol 2013;25:146-51. 